\title{
archivo
}




\title{
El gran archivo. El arte desde la burocracia
}

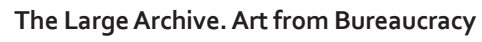 \\ O grande arquivo. Arte desde a burocracia
}

\section{Sven Spieker}

UNIVERSITY OF CALIFORNIA, SANTA BARBARA, ESTADOS UNIDOS

Profesor del Departamento de Estudios Germánicos y Eslavos, University

of Califonia, Santa Barbara. PhD Oxford University. Ha publicado The

Big Archive. Art from Bureaucracy (MIT Press, 2008), The Imprints

of Terror. The Rhetoric of Violence and the Violence of Rhetoric in

Modern Russian Culture (Vienna, 2006; editado con Anna Brodsky

y Mark Lipovetsky), Bürokratische Leidenschaften. Kultur- und

Mediengeschichte im Archiv (Kadmos, 2004), GOGOL: Exploring

Absence. Negativity in 19th-Century Russian Literature

(Slavica, 2000) y Figures of Memory and Forgetting in Andrei

Bitov's Prose (Peter Lang, 1996). Spieker es Editor de ARTMargins

(www.artmargins.com). Correo electrónico: spieker@gss.ucsb.edu

Ensayo

Documento accesible en línea desde la siguiente dirección: http://revistas.javeriana.edu.co

Ensayo publicado originalmente en The Big Archive. Art From Bureaucracy. Cambridge: MIT Press, 2008.

Traducción de Wilfredo Hernández y Camila Pulgar Machado

Wilfredo Hernández es profesor del Departamento de Idiomas Modernos y Clásicos

en Allegheny College, Pensilvania, EE.UU. Doctorado en Español por la Universidad

de Connecticut. Correo electrónico: whernand@allegheny.edu

Camila Pulgar Machado es profesora de la Escuela de Letras de la Universidad Central de Venezuela.

Magíster en Estudios Literarios por la misma universidad. Obtuvo la beca Fulbright (2013-2014), con

la cual desarrolló su investigación doctoral en el Departamento de Literatura y Lenguas Hispánicas

de la Universidad de Pittsburgh. Correo electrónico: camilapulgarmachado@gmail.com

doi:10.11144/Javeriana.cl21-41.gaab

Cómo citar este ensayo:

Spieker, Sven. "El gran archivo. El arte desde la burocracia". Cuadernos de Literatura

21.41 (2017): 15-29. https://doi.org/10.11144/Javeriana.c121-41.gaab 


\section{Introducción}

En este libro investigo el modo en que el archivo burocrático le dio forma a la práctica artística en el siglo XX, del montaje dadaísta a la instalación finisecular. Más específicamente, propongo que el uso de archivos en el arte de fines del siglo XX reacciona en una variedad de formas al asalto de las vanguardias de los inicios de esa centuria contra la objetivización (y fetichización) del tiempo lineal y el proceso histórico. A lo largo del ensayo espero hallar respuestas tentativas a algunas interrogantes formuladas por Allan Sekula en el ensayo "El cuerpo y el archivo": " ¿Hasta qué grado la práctica modernista autorreflexiva se acomodó al modelo del archivo? ¿Hasta qué grado los modernistas, consciente o inconscientemente, resisten o subvierten el modelo del archivo?" . Al archivo al que hace referencia Sekula se lo percibe como una clave del sueño moderno del control total de la abarcadora disciplina administrativa; es decir, como un gigante archivero en el centro de una realidad fundada en una racionalidad ordenada. Espero, entre otras cosas, revelar una alternativa a esta noción dominante; alternativa que exponga el lado irracional de la conexión archivística de la modernidad y que le dé a esta su necesaria tracción histórica.

Hace pocos años vi en una exposición en París algunas de las "Cápsulas temporales", de Andy Warhol; una obra seriada formada por 610 cajas de cartón de tamaño estándar que, empezando en 1974, el artista llenó y luego envió a guardar en un depósito. Para Warhol estas cajas eran una extensión de las gavetas de su escritorio; contenían diversos tipos de documentos: invitaciones a cenar, correspondencia personal, impresos, fotografías y recuerdos de viajes que llegaban a diario a su estudio y que, en ocasiones, se recibían sin que se les prestara mucha atención. Archivar estos materiales significaba depositarlos en una caja convenientemente ubicada cerca de su escritorio. Cuando se llenaba, se la sellaba y se la reemplazaba por una nueva. En el taller de Warhol, que en este caso lucía como un archivo repleto, los documentos se guardaban en la caja, no porque fueran importantes, valiosos o de otra forma memorables, sino porque estaban "allî", sobre el escritorio; como una fotografía capta lo que está en cierto tiempo en un lugar determinado. Las cajas me parecían elementos sin mucha relevancia hasta que una pequeña colección de objetos del avión Concorde (servilletas, boletos, cubiertería) que Warhol había traído de uno de sus viajes transantlánticos, atrajo mi atención. Semanas antes de que yo visitara la exposición, un Concorde había explotado cerca de la capital gala y todos los pasajeros habían perecido. De manera extraña, era como si la presencia de estos objetos en el archivo de Warhol solo una semana después del fatal accidente

$1 \quad$ Allan Sekula. "The Body and the Archive". October 39 (1986): 58. 
conmemorara un evento: el trauma de todos los fallecidos tres décadas después, lo que obviamente no había aún ocurrido cuando se creó el archivo. Mi experiencia con las cajas de Warhol parece indicar que los registros archivísticos raramente coinciden con lo que nuestra conciencia es capaz de registrar. Los archivos no guardan tanto los registros de la experiencia como más bien su ausencia; señalan el punto en donde una experiencia está ausente de su lugar apropiado, y lo que se nos ofrece quizá puede ser algo que nunca poseímos. ¿ Hay una parte del archivo que escape del control del archivista, un "más allá del archivo" que permanence inaccessible a las entradas de su fichero? Ese más allá puede describirse como un unheimlich, término cuyo origen etimológico (del alemán Heim [hogar] y heimlich [secreto, escondido]) lo liga al archivo en más de un sentido. ${ }^{2}$ En la explicación de Freud, ${ }^{3}$ lo misterioso indica el regreso inesperado de un registro que conocemos como familiar a pesar de no aparecer en nuestro gabinete archivero. No es de extrañar que la aparición de un documento perdido sea recibido con miedo y malestar. Cuando los documentos vuelven a ocupar su lugar en un archivo, pensamos que está completo. Sin embargo, con cada registro en su lugar correcto, debidamente catalogado y justificado, el proyecto modernizador de la racionalidad basada en la realidad y el orden, colapsa: y el archivo se convierte literalmente en un lugar embrujado.

Los archivos no nos reconectan simplemente con lo que hemos perdido; en cambio, nos permiten recordar, como las cajas de Warhol, lo que nunca hemos poseído en primer lugar. Si esa es una paradoja, es quizá la paradoja de la modernidad misma, si por modernidad entendemos una serie de protocolos que gobiernan la producción y transmisión de la cultura de un lugar que, por definición, no es el lugar del sujeto; no es simplemente nuestro lugar. El arkheion, la base material del archivo o sustrato, no es simplemente un lugar para los recuerdos. Según Yosef Hayim Yerushalmi: "Ni la memoria es un archivo, ni un archivo es un banco de recuerdos. Los documentos en un archivo no son parte de la memoria; si lo fueran, no tendríamos necesidad de buscarlos. Una vez encontrados, están fuertemente en disputa con la memoria". ${ }^{4}$ Donde las colecciones no son archivos, sí ofrecen un lugar de morada a sus propietarios (en palabras

2 El término archivo se deriva del griego arckhe (comienzos u origen) y arkheion (casa o domicilio, el hogar de los custodios de los documentos oficiales) e implica una referencia a ambos, tanto al comienzo u origen, como al lugar específico o localización en que se guardan los archivos.

3 Sigmund Freud, "The Uncanny". Standard Edition of the Complete Psychological Works of Sigmund Freud, ed. James Strachey, vol. 17 (London: Hogarth Press and the Institute of Psycho-Analysis, 1955), 220. La obra se citará de ahora en adelante como SE.

4 Yosef Hayim Yerushalmi, "Series Z: An Archival Fantasy", http://www.psycomedia.it/uep/ number3-4/yerushami.htm. 
de Walter Benjamin, "la posesión es la relación más íntima que uno puede tener con los objetos. No que ellos vivan en uno, sino, por el contrario, somos nosotros los que vivimos en ellos" ${ }^{9}{ }^{5}$ los archivos, en cambio, en raras ocasiones ofrecen refugio. François Lyotard ha descrito la diferencia entre el domus como un hogar (una colección) de recuerdos y el archivo con gran precisión. Para él, el espacio del domus es hogareño y primordial; un espacio organizado por los ritmos de los relatos orales que articulan la cultura como una experiencia personal. El domus es la manera de Lyotard de referirse a la vida humana vivida dentro de los pliegos de la naturaleza: "las narraciones son como gestos, relacionados con contorsiones, lugares, nombres propios". En el domus "hay narraciones: las generaciones, la localidad, las estaciones, la sabiduría y la locura. La narración crea el comienzo y termina con rima, marca las interrupciones" ${ }^{6}$ El lugar contrario al domus es la residencia urbana oficial (el arkheion) en donde las casas no son hogares sino archivos, oficinas y agencias, y en donde la transmisión de la cultura ha pasado a ser no materia de narración sino de listas. En la ciudad, en donde el domicilio reemplaza al domus como el lugar de la transmisión de la cultura, las antiguas mónadas domésticas se dispersan. El domicilio es el lugar en el que las personas, los objetos y los animales que habitan el domus están sujetos al catálogo, al inventario y a la administración por letras y números. Allí el conteo toma el lugar del recuento y la identificación el lugar de los gestos. El domicilio es la clave de una edad de archivización en que la memoria es del dominio de los medios técnicos, de los signos, del depósito más o menos sistemático o, según palabras de Lyotard, "la anonimia de los archivos". 7

En el arte y la crítica del arte del tardío siglo XX, el archivo deviene el tropo por excelencia para una variedad deslumbrante de actividades. Sin embargo, parece haber poco consenso sobre qué es un archivo, cómo puede distinguirse de otros tipos de colecciones y, quizá más importante, cómo puede enmarcarse su relación temprana con el arte del inicio del siglo XX, más notablemente con las vanguardias históricas. ${ }^{8}$ Una perspectiva diacrónica del archivo es central en

5 Walter Benjamin, "Unpacking My Library", en Benjamin, Illuminations (New York: Schocken, 1969), 61 .

6 François Lyotard, "Domus and the Megalopolis", en Lyotard, The Inhuman: Reflections on Time (Stanford: Stanford University Press, 1991), 192, 193.

$7 \quad$ Ibid., 194.

8 Para un intento de debatir esta situación, ver The Archive, de Charles Merewether, una compilación de ensayos completos y declaraciones que iluminan la atiborrada intersección del archivo y el arte. En su introducción, Merewether plantea que "es en las esferas del arte y la producción cultural que algunas de las preguntas más inquisitivas han sido formuladas con 
mi proyecto, que también toma en cuenta que, aunque los archivos han existido desde que los humanos comenzaron a administrar sus vidas, las modalidades técnicas del depósito archivístico se han modificado incesantemente con el paso del tiempo. ${ }^{9}$ Entre las tecnologías archivísticas cuyo uso se generaliza en el arte del siglo XX, y que trato con cierta extension, están las máquinas de escribir, el fichero y la carpeta. Estas tecnologías están en el centro de lo que James Beniger denominó la "Revolución del control" en el periodo 1880-1930, una reacción a la pérdida de control económico y político . . . en . . . los niveles locales de la sociedad durante la Revolución Industrial. Antes de esa época, el control del gobierno y del mercado había dependido de relaciones personales e interacciones cara a cara; ahora el control se reestableció mediante la organización burocrática y las nuevas infraestructuras de transporte y comunicaciones, así como los nuevos medios de comunicación masiva. ${ }^{10}$

La revolución del control pasó a ser una realidad, según Beniger, gracias, primero, a la moderna burocracia racionalizante; y segundo, a las tecnologías de las comunicaciones desarrolladas casi contemporáneamente. No obstante, los

relación a lo que constituye un archivo y qué autoridad tiene con respecto a su sujeto". Charles Merewether, ed., The Archive (London: Whitechaple: Cambridge: MIT Press, 2006), 10.

9 Mi interés en los archivos no está confinado al arte en Europa Occidental o los Estados Unidos. Llegué al tema gracias a mi inclinación por el arte contemporáneo de los antiguos países comunistas del centro y el este de Europa, región en donde todo el mundo vivió, con grados diversos, a la sombra del archivo; y en donde la pregunta del archivo y su relación con el arte fue, y aún es, todo menos académica. Quizá el recordatorio más memorable sea El gran archivo (1993), de Kabakov, del cual tomé prestado el título para este libro. Al entrar en la instalación y leer los mensajes manuscritos y las planillas que están pegados en todas sus monótonas paredes divisorias, el visitante pronto se da cuenta de que es parte del inventario del archivo. Una especie de selección clasifica a todo visitante: «Cerca de la entrada de cada sección [en que el archivo está dividido] hay una inscripción sobre el tipo de visitante al que está dirigida: "enfermos", "insatisfechos con sus condiciones de vida", "los que planifican", "los residentes permanentes en el país", "los que han estado en prisión". Cada persona debe ser propietaria de algo, responder a algo, firmar para algo». Ilya Kabakov, citado en Amei Wallach, Ilya Kobakov: The Man who Never Threw Anything Away (New York: Harry N. Abrams, 1996), 209. Los formularios en los escritorios del archivo invitan a los espectadores a confirmar mediante su firma que están listos para aceptar el cargo que el archivo ha reservado para ellos. Como archivo, El gran archivo comienza a existir precisamente en ese punto, conocido por todo aquel que haya vivido en la Unión Soviética y/u otros países del antiguo Bloque Oriental; en el cual nos damos cuenta de que una perspectiva del archivo desde un ángulo exterior a él, es imposible.

10 James R. Beniger, The Control Revolution: Technological and Economic Origins of the Information Society (Cambridge: Harvard University Press, 1986), 37. 
medios tecnológicos mediante los cuales se estableció, también trajeron consigo un riesgo, por entonces desconocido, de una asombrosa pérdida de control. El problema estuvo en que las máquinas de las oficinas en uso generalizado entre 1870 y 1920, de la máquina de escribir al fichero, no solo procesaban registros existentes a una velocidad inusitada, sino que también producían registros de nuevos datos. Por ejemplo, con la introducción de las copias al carbón, la máquina de escribir, sin discusión uno de los útiles más efectivos en crear la revolución del control, se convirtió en una máquina copiadora tan altamente eficiente que intensificó la crisis que estaba diseñada para conquistar. ${ }^{11}$ Considero la primera modernización del siglo XX como una formación que responde a la crisis de la falta de espacios o depósitos que ocurrió en la víspera de la revolución propuesta por Beniger, una gigantesca obstrucción de papel basada en el incremento exponencial de la información archivada tanto en el ámbito de la administración pública como en las grandes compañías cuyas oficinas de registros estuvieron prontamente abarrotadas hasta los topes.

El archivo en que me concentro en este libro no es el del siglo XVIII, con sus tablas clasificatorias, cuadrículos vacíos y esquemas abstractos para la organización del conocimiento. ¿Qué separa el archivo dieciochesco de su sucesor decimonónico? En pocas palabras, la confianza en la posibilidad de guardar registro del tiempo contingente en la forma de trazos discretos; la esperanza de que el momento presente, la contingencia en sí misma, pueda convertirse en objeto de medición y registro. En el siglo XIX, la función de los archivos pasó de ser la de depósitos de títulos legales a la de lugares en que los historiadores esperaban hallar los sedimentos del tiempo mismo. No la historia, me apresuro a agregar, sino el tiempo en flujo y avanzando. Esta preocupación por lo contingente, por el momento presente y por la posibilidad de su archivo tuvo importantes consecuencias. Obsesionado con la idea de que no había nada en la naturaleza o la cultura que no pudiera explicarse sin recurrir al tiempo, el siglo XIX no solo expandió considerablemente la definición de lo que constituye un registro, sino que también amplió considerablemente el alcance del archivo encargado de coleccionar tales datos.

Si puede discutirse que las colecciones que no son archivos están ligadas al orden de lo que Lacan denomina el Imaginario, y la biblioteca de libros a lo Simbólico, entonces, el archivo decimonónico, con su ambición de registrar el

\footnotetext{
11 Ver también Cornelia Vismann, Akten: Medientechnik und Recht (Frankfurt: Fischer, 2000), 274.
} 
tiempo contingente, se alinea con el orden (el desorden) de lo Real. ${ }^{12}$ Crucialmente, la creencia extendida en el siglo XIX de que los archivos tenían la posibilidad de registrar lo que elude representación simbólica, tiene sus bases en la realidad de que eran compilados por razones mayormente legales; razones que eran diferentes de las de los historiadores que los visitaban. ${ }^{13}$ Cuando uno de los historiadores más prominentes del siglo XIX, Leopold von Ranke, afirmó que quería "borrar mi propio yo para dejar que solo las cosas hablen", ${ }^{14}$ su declaración reflejaba la confianza de que en un archivo el historiador, confinándose debidamente a sí mismo a una pasividad más o menos completa, confrontaría los sedimentos de fuerzas y procesos cuya autoridad estaba apoyada en el hecho de que no se encontraban registrados allí. Tal confianza en la heterotopia, la idea de que el poder de evidenciar del registro constituye una reflexión sobre su origen que acontece en un lugar otro, distinto al que el archivo preserva, no estuvo limitada a los historiadores. En las ciencias también hubo una creencia extendida de que la archivización de las fuerzas de la naturaleza podría convertirse en una realidad solo si los métodos (mecánicos) de inscripción fueran exitósamente hallados al punto de superar la representación simbólica, de tal modo que el "otro lugar", en última instancia el tiempo mismo, pudiera ser inducido a crear su propio archivo (Marey; Anschütz).

El archivo del siglo XIX, a través de varias disciplinas, desde la historiografía hasta las ciencias naturales, tuvo un impulso duradero en el arte de comienzos del siglo XX. Sin embargo, antes que apoyar la confianza decimonónica en el registro del tiempo, los miembros de las vanguardias del siglo XX criticaron y, en última instancia, desmantelaron esa confianza de tres maneras: primero, señalando que la contingencia y el azar pueden afectar literalmente todas las operaciones archivísticas a todo nivel (Marcel Duchamp); segundo, compilando colecciones de momentos de ruptura que eludían el archivo (el surrealismo temprano); y tercero, cuestionando las bases newtonianas de la topografía del archivo y sus correlativos ópticos usando el cine (El Lissitzky, Sergei Eisenstein). En estos tres ejemplos el archivo funciona simultáneamente como un laboratorio para indagaciones experimentales en el lado irracional del siglo XIX y como una elaboración de un tipo de visualidad en la que archivar es clave. Como Rosalind Krauss ha planteado, cualquier evaluación del

12 Sobre la diferencia entre archivos y bibliotecas, ver T. R. Schellemberg, Modern Archives: Principles and Techniques (Chicago: University of Chicago Press, 1956), 22-23.

13 "Para ser archivos, los materiales deben ser preservados por otras razones distintas que para las que fueron creados o acumulados". Ibid., 13.

14 Leopold von Ranke, "Englishsche Geschichte vornehmlich im siebzehnten Jahrhundert", en Ranke, Sammtliche Werke, vol 14 (Leipzig: Duncker und Humblot, 1870), 103. 
ataque de la vanguardia contra la autonomía del arte y, específicamente, del museo, sería incompleta si no se consideraran los fundamentos cognitivos y visuales de esa autonomía. ${ }^{15}$ La vision modernista se identifica frecuentemente con una mirada que no archiva, ideal y vacía; que no conoce ni objetos ni sujetos, descrita por Foucault como "la ingenuidad brillante, distante y abierta de la mirada". ${ }^{16}$ Evaluar el ataque de las vanguardias a este tipo de autonomía no archivística que, según Krauss, alcanzó su cima en el impresionismo y el neoimpresionismo, es confrontar un modelo de mirada para el cual el archivo es relevante, no como una cuadrícula vacía e ideal esperando que se la llene con objetos, sino como un lugar al cual los objetos regresan ya fabricados. ${ }^{17}$ En esta lectura la pureza libre de la modernidad, su devoción por el origen como una salida absoluta, el famoso "sin borrones" (la mirada límpida), puede funcionar solo hasta el punto al que nosotros marginemos el archivo en que está fundada.

Un cuestionamiento decisivo al archivo decimonónico fue el montaje de los dadaístas (colage, colección, fotomontaje). Cuando Francis Picabia destrozó un reloj suizo, mojó sus partes en tinta e imprimió su marco en papel (Reloj despertador I, 1919) no solo cambió el orden en desorden sino que también transformó un mecanismo en funcionamiento en una colección de sus partes a través de los medios de reproducción, permitiendo así que estas partes entraran en una nueva serie de relaciones. No sorprende que estas relaciones no imitaran simplemente las de un reloj en funcionamiento, del tiempo medido y domado. Es decir, el procedimiento de Picabia tiene implicaciones importantes para medir el tiempo; una tarea asociada con la de los archivos y los relojes. Si estos últimos están investidos en una comprensión del tiempo como una progresión lineal de momentos, la colección de partes mecánicas reproducida por Picabia sugiere un archivo basado en el regreso y la reproducción. De tal manera, esto bien pudiera ser emblemático de la aproximación archivística generalizada de los dadaístas. Como abstracciones que tratan las piezas clavadas o pegadas al plano pictórico, el colage y el montaje dadaístas pertenecen de lleno a la esfera de lo no archivable. Sin embargo, como investigaciones sobre las relaciones entre imagen y plano pictórico, forman parte de una modernidad basada en el

\footnotetext{
Rosalind E. Krauss, "The Master's Bedroom", Representations 28 (1989): 56.

Michel Foucault, The Birth of the Clinic: An Archeology of the Medical Perception, trad. A. M. Sheridan Smith (New York: Pantheon Books, 1973), 65.

"Porque lo que se proyecta aquí es un campo visual que no es una latencia, ni un crecimiento permanentemente renovado por la potencialidad pura de lo externo, sino un campo que ya está lleno, y para decir la palabra, readymade [fabricado]". Krauss, "The Master's Bedroom", 65.
} 
archivo, no porque apoyen el archivo decimonónico, sino porque lo cuestionan y subvierten.

Creado con basura reciclada (pedazos de tela, madera, recortes periodísticos, reproducciones fotográficas, barajas) montada en una base de manera pseudo arqueológica, el montaje dadaísta funciona como un anti-archivo que no solo reacciona al traumatizante embotellamiento de papel ocurrido en la víspera de la Primera Guerra Mundial (ningún otro evento histórico había generado tanto papel), sino también se rehúsa a apoyar la conversion de basura en cultura que había hecho el archivo del siglo XIX. Walter Benjamin se ha referido a esta operación como una reacción de los dadaístas al haberse dado cuenta de que el establecimiento del orden se había convertido en una imposibilidad: "montaron boletos de tren, pedazos de vidrio, botones, fósforos, y decían: no puedes manejar la realidad. Ni este montoncito de basura, ni el movimiento de las tropas, ni la epidemia de influenza, ni los billetes". ${ }^{18} \mathrm{Si}$ según Benjamin el montaje dadaísta cuestiona la llamada al orden, la mathesis general que enfatiza la racionalidad de la iluminación (y del arte tradicional) en el contexto destructivo de la Primera Guerra Mundial, en el proceso también desafía la idea de que, en medio de tal desorden generalizado, la producción artística pueda ser algo más que una forma de archivar; una llamada a la presencia fragmentaria de objetos materiales sin preocuparse por el pasado o el futuro. ${ }^{19}$

Como una forma de reproducción que depende de archivar fragmentos de la realidad que se toman fuera de su contexto acostumbrado, y que son luego depositados y redistribuidos, el montaje dadaísta puede verse como un ejemplo de revelación (Entbergen) heideggeriana. En su conferencia "La cuestión sobre la tecnología", Heidegger separó la creación como una forma de revelación, por un lado, de la creación absoluta (poiesis), por otro, relacionando la primera con la tecnología moderna. A diferencia de la poiesis, que implica un cambio directo de la ausencia a la presencia, Entbergen desvela y transforma lo que ya está presente pero aún es invisible. ${ }^{20}$ Sin embargo, si el montaje dadaísta es revelatorio en un

18 Walter Benjamin, "Bekränzter Eingang: Zur Ausstellung 'Gesunde Nerven' im Gesundtheitshaus Kreuzberg", en Benjamin, Gesammelte Schriften, vol. IV. 1, 2 (Frankfurt: Suhrkamp, 1980), 556. Traducción del alemán al inglés de Sven Spieker.

19 Similarmente, mucho de los primeros relieves hechos en madera por Hans Arp abandonan la idea de una base.

"La revelación de que las reglas a lo largo de la tecnología moderna tienen el carácter de un asalto crítico, en el sentido del desafío de la idea. Ese cuestionamiento ocurre cuando la energía escondida en la naturaleza se libera, lo que se libera se transforma, lo que se transforma se deposita, lo que se deposita es, a su vez, distribuido, y lo que es distribuido es cambiado siempre de nuevo. Liberar, transformar, depositar y distribuir son maneras de revelación". Martin Heidegger, The 
sentido, es oscurantista en otro. Por ejemplo, las capas de formas cuidadosamente cortadas y arregladas en muchas obras de Kurt Schwitters (quien miraba los documentos postales como la forma "última" de la realidad y derivaba los sonidos de su Ursonate de las palabras abreviadas en letreros de compañías y cartas con membretes), ${ }^{21}$ que apuntan a la misma base de apoyo, sustrato sin el cual ningún archivo podría existir. Pero al indicarlo, estas formas oscurecen esa base a cada paso y nos llevan a preguntarnos qué es fondo y qué es imagen. A veces, Schwitters incluso usa una de sus propias pinturas como la base de apoyo para sus colages y colecciones; procedimiento diseñado para frustrar aun más nuestra expectativa de que la base de apoyo, como un lienzo vacío, podría concebirse como una especie de suelo virgen o cuadrícula sobre la que una imagen descansa. Al tener sus imágenes irreparablemente rotas, el montaje irregularmente colocado no solo oscurece progresivamente su base sino que también promueve elementos individuales sobre los que nuevos elementos encajan en el estatus de bases locales nuevas. Como cada elemento en el plano se convierte potencialmente en el apoyo más cercano para otro, el montaje dadaísta refracta y redobla el plano (completo) de la base con numerosos planos rivales (rotos), subrayando el hecho de que en un archivo la relación entre el sustrato, la base del archivo y lo que guarda no es siempre dada. Esto tiene consecuencias importantes para nuestra recepción de estas obras porque nuestra mirada casi nunca está en descanso, ya que se mueve constante (y erráticamente) entre imagen y texto, el nivel de la base y la superficie, en un movimiento que se resiste con resolución a la contemplación.

El montaje dadaísta promueve el archivo de partes rotas como una interrupción de la racionalidad de los medios-fines, que gobierna la realidad social y política. Más allá de eso, promueve una ligazón crucial con un medio que ilustra el reclamo del archivo moderno a lo Real como ninguno otro: el cine. ${ }^{22}$ Como Dorothea Dietrich escribe en su discusión de Pintura de cereza (Merzbild 32A) (1921), "el ojo constantemente salta entre descifrar un texto y mirar una imagen, más o menos de la misma forma que el ojo se mueve de la imagen de la cereza en la tarjeta al texto debajo de la imagen, hacia la identificación de palabras, y de allí salta entre los dos

Question Concerning Technology, and Other Essays, trad. William Lovitt (New York: Garland, 1977), 16. Para un comentario reciente sobre el concepto de Entbergen en Heidegger, ver Peter Sloterdijk, Nicht gerettet: Varsuche nach Heidegger (Frankfurt: Suhrkamp, 2001), 287.

21 Para un ejemplo de abreviaciones usadas en la organización de archivos de oficina durante la década de 1920, ver Vismann, Akten, 296-297.

22 En su estudio del tiempo contingente y el cine, Mary Ann Doanne observa que "se ha trabajado el cine para confirmar la legibilidad de lo contingente". Mary Ann Doanne, The Emergence of Cinematic Time: Modernity, Contingency, the Archive (Cambridge: Harvard University Press, 2002), 208. 
lenguajes solo para regresar otra vez a la imagen. Nuestro ojo ... [se mueve] hacia atrás y hacia adelante en una pista entre diversas opciones de lectura". ${ }^{23}$ Dietrich señala que este proceso, que se despliega con el tiempo, tiene una deuda con la lectura porque la imagen se consume como texto. Sin embargo, podemos plantear con igual justificación que la manera en que nuestra mirada se desplaza hacia atrás y hacia adelante entre los diferentes elementos, es más parecida, estructuralmente, a mirar una película. A diferencia de los fotomontajes de John Heartfield, que, como Peter Bürger ha escrito, combinan imagen y texto linealmente, a la manera de los antiguos emblemas, en los montajes de Schwitters la relación entre la imagen y las palabras está mayormente desencajada, en tanto que el texto y las imágenes rara vez parecen corresponder exactamente entre ellas. ${ }^{24}$ Esto significa que aunque podemos leer fragmentos de texto que existen en muchas obras de Schwitters, tal lectura nunca alcanza a integrar completamente el texto con su imagen. En donde la lectura lineal presupone la concentración y la habilidad de "seguir la línea", las superficies rotas del montaje dadaísta, muy similar al montaje cinematográfico, estimulan un modo receptivo caracterizado por la distracción, una falta de dirección lineal y repetidas entradas y salidas desvaneciéndose. $\mathrm{Y}$ aquí radica precisamente su importancia para la elaboración dadaísta del anti-archivo. Obras como Pintura de cereza son archivísticas, no solo en el sentido de que constituyen sitios de depósito para los fragmentos descartados y alienados de un orden simbólico destrozado, sino que también son analíticas de la relación entre la base del archivo y sus áreas de depósito. El montaje dadaísta insinúa que es la relación entre estos dos estratos o, más bien, su persistente interferencia y oscilación, nuestra dificultad en diferenciar uno del otro, lo que condena al fracaso el proyecto decimonónico de integrar el archivo con el tiempo contingente.

En su ataque a las bases del archivo del siglo XIX, el montaje dadaísta marca el primer momento dinámico en la elaboración de un tipo de modernidad en la que el archivo es clave. En el arte del tardío siglo XX, que analizo en los dos últimos capítulos de esta obra, el archivo se define en la ex-Europa oriental comunista por las manipulaciones de la era stalinista y la inercia que le siguió; y en Occidente, por la codificación social de la amnesia generalizada por los medios de comunicación masiva. En los países del exbloque soviético, los medios de reproducción técnica y archivo, que la vanguardia histórica había visto como órganos emancipadores de un nuevo cuerpo social colectivo recién mecanizado, fueron

\footnotetext{
23 Dorothea Dietrich, sin título, en Leah Dickerman, ed., Dada, exh. cat. (Washington: National Gallery of Art, 2006), 163.

24 Peter Bürger, Theory of the Avant-Garde (Minneapolis: University of Minnesota Press, 1984), 75.
} 
declarados monopolio estatal (en la ex-Unión Soviética la propiedad personal de máquinas de escribir estaba incluso regulada por el Estado), transformando el sujeto social colectivo capaz de ser archivable, previsto por la vanguardia (a cada quien su cámara fotográfica), en un objeto fragmentado y archivable por los casi ubicuos sistemas de vigilancia audiovisual.

Los artistas de mediados de las décadas de 1960, 1970 y en adelante, un periodo a menudo asociado con el surgimiento de la información en o como arte, amplificaron la crítica de la vanguardia sobre el historicismo del siglo XIX, concibiendo el archivo como las reglas y los protocolos que son imprescindibles para la producción del arte, más o menos en la vena del a priori histórico de Michel Foucault. El archivo que Foucault bosqueja en muchas de sus obras tempranas, no es una gramática de reglas abstractas y paradigmas ni un inventario de registros reales; es más bien un archivo cuyas reglas se construyen junto con (al mismo tiempo que) las que ellas ayudan a formular. Las reglas que se especifican en el a priori histórico de Foucault, no se imponen desde el exterior, sino que emergen del archivo mismo, "atrapadas en las mismas cosas que conectan". ${ }^{25}$ Como el a priori histórico, el archivo en obras de artistas que van desde Susan Hiller y Gerhard Richter, hasta Walid Raad y Boris Mikhailov, no es ni simplemente una gramática de reglas abstractas ni un depósito de información; más bien es una gramática (un modelo) cuyas reglas se constituyen en sí mismas junto con los principios que ayudan a formular. Fichero: 11 de julio - 31 de diciembre de 1962, de Robert Morris, es un ejemplo de ello. Formada por un índice cardex fabricado industrialmente y operado manualmente, con un arreglo de niveles casi arqueológico, sus páginas individuales reflejan el proceso de su propia producción. En la manera en que conecta palabras con el depósito del proceso, Fichero es tanto un archivo como una guía referencial para la producción de arte. Por ejemplo, la página con la identificación "decisión" contiene una lista de las primeras páginas del documento y las fechas en que fueron creadas; mientras que la sección rotulada como "errores" tiene una lista de los errores ortográficos presentes en las otras páginas. Otros folios incluyen "título", con listas de los títulos de obras, y "firma", que contiene la firma del artista.

El hecho de que Morris establezca la relación de su archivo con el tiempo ("11 de julio a 31 de diciembre de 1962") mediante el uso de las palabras, vincula

25 "El análisis del archivo involucra, entonces, una región privilegiada, al mismo tiempo cercana a nosotros y diferente de nuestra existencia presente; es la frontera de tiempo que rodea nuestra presencia, que sobresale de ella y que indica su otredad. Es lo que fuera de nosotros nos delimita". Michel Foucault, The Archeology of Knowledge and the Discourse on Language (New York: Pantheon Books, 1972), 130. 
su archivo tanto con los esfuerzos del siglo XVIII de establecer un orden archivístico como con la crítica de ese esfuerzo que emergió durante el siglo XIX. Como Foucault ha demostrado, en el siglo XIX el lenguaje ya no servía como un instrumento de clasificación, como lo había sido en el siglo XVIII, cuando el archivo como sistema de categorías formales discursivas se había usado para clasificar el mundo. En cambio, el lenguaje se convirtió en un objeto de indagación con derecho propio. Con el surgimiento de la filología en el siglo XIX, el lenguaje adquirió un estatus privilegiado, como el murmullo denso y opaco de la vida cuyo cuestionamiento sostenido por parte de científicos, filólogos y filósofos, desde Nietzche a Marx y a Freud, ofrecía una vislumbre de lo que nos capacita para hablar en primer lugar: "La verdad del discurso está atrapada en las trampas de la filología. De allí la necesidad de desplazar nuestra indagación de las opiniones, las filosofías y quizá aún más de las ciencias, hacia las palabras que las posibilitan y, más que eso, hacia un pensamiento cuya vida esencial aún no ha sido atrapada en la red de ninguna gramática". ${ }^{26}$ Tratando las palabras como "tantos objetos formados y depositados por la historia", ${ }^{27}$ en breve, como un archivo, la filología decimonónica opuso el archivo contra el orden gramátical y lingüístico del siglo XVIII con el fin de que el secreto del archivo ("un pensamiento cuya vida esencial aún no había sido atrapada en la red de una gramática") no fuera encontrado en ninguna parte, excepto en el flujo del tiempo mismo.

¿Continúan Morris y el arte del tardío siglo XX, en general, el cuestionamiento del archivo de las palabras que Foucault ve como el centro de gravedad del siglo XIX? Regresando a Fichero, es curioso que su efecto como archivo derive en parte de las formas que emplean tanto los paradigmas de los siglos XVIII como los del XIX, sin tomar partido por ninguno. En su uso de palabras en los rótulos para propósitos clasificatorios, el archivo de Morris supera la metafísica archivística del siglo XIX (el archivo que transcribe los murmullos del tiempo mismo), regresando en cambio al uso del lenguaje del siglo XVIII para propósitos de clasificación formal. Aun en su insistencia en las capas arqueológicas y la preservación del proceso, Fichero también confirma ese paradigma, aunque con un giro importante. A pesar de que la distribución industrial en niveles recuerde el modelo arqueológico que caracteriza el archivo decimonónico, lo que se guarda en el archivo de Morris no tiene poder de evidencia más allá del proceso de su propia producción. Esto, sin embargo, significa no menos que el alejamiento del archivo de lo que había consti-

26 Michel Foucault, The Order of Things: An Archeology of the Human Sciences (New York: Vintage Books, 1973), 297.

27 Ibid., 304. 
tuido su Lebenskraft esencial en el siglo XIX, es decir, la idea de que los archivos nos conectan al tiempo mismo al atraparlo inadvertidamente. Como textos, los rótulos que organizan el Fichero de Morris ya no tienen el poder de testimoniar ni el orden ni el discurso del siglo XVIII, ni mucho menos la noción de historia como proceso infinito vigente en el siglo XIX. Lo que Robert Smithson explicó en una entrevista en 1972 sobre sus Cámaras enantiomórficas (1964) también puede aplicarse a Morris: "Y creo que las Cámaras enantiomórficas fue la pieza que realmente me liberó de todas estas preocupaciones con la historia; estaba trabajando con cuadriculados, planos y superficies vacías. Las formas cristalinas sugerían trazar un mapa". ${ }^{28}$ Es precisamente el mapa lo que viene a rivalizar con el archivo del siglo XIX en el arte de fines del siglo XX.

Pese a ciertos saltos ocasionales, los capítulos del libro siguen un orden cronológico. Comienzo con una introducción al archivo decimonónico y luego analizo algunas facetas de la práctica archivística de la vanguardia antes de tratar los usos de los archivos en la práctica artística contemporánea. En el segundo capítulo explico algunas de las suposiciones científicas, administrativas y estéticas del archivo del siglo XIX. Luego examino uno de los esfuerzos más sofisticados de tratar con las consecuencias de la expansion radical del archivo en el siglo XIX: el psicoanálisis freudiano. Mi interés en ese capítulo radica en la administración de Freud del psicoanálisis y su elaboración de un modelo de la psique que comparte características importantes con el archivo del historicismo del siglo XIX; en particular, la esperanza de que el archivo pueda dar acceso, dentro de los confines del momento presente, a "otro territorio".

En el cuarto capítulo considero la preparación y la amplificación hecha por Marcel Duchamp de la crítica dadaísta del archivo decimonónico, enfocándolas en la posibilidad de que la contingencia (el azar y el accidente) puedan afectar la estructura del archivo mismo. Los ready-mades de Duchamp, que se interpretan frecuentemente como nada más que investigaciones con el poder de nombrar, proponen que la contingencia y la posibilidad de un accidente radica en el mismo centro de cualquier esfuerzo de registrar y medir el tiempo; y que la incursión del azar afecta el archivo a todo nivel. Mientras los archivos del siglo XIX actúan comúnmente como edificios de depósito acumulativo de una cantidad siempre creciente de evidencias, los ready-mades contrarrestan este modelo con una

28 The Writings of Robert Smithson: Essays with Illustrations, ed. Nancy Holt (New York: NYU Press, 1979), 287. 
tendencia pronunciada hacia el adelgazamiento y la disminución; el archivo de Duchamp es radicalmente anémico.

En el quinto capítulo analizo la crítica que el primer surrealismo le hizo al archivo del siglo XIX, basándose en las nociones de procedencia y orden original. Donde el siglo XIX consideraba toda sub specie historiae, los surrealistas establecen un archivo de lapsus de la historia; un archivo de lo que sale fuera del tiempo. Teniendo como punto de partida el archivo abierto por los surrealistas en 1924 en el corazón de París, muestro que el proyecto del primer Surrealismo está dirigido a desbaratar la metafísica archivística del siglo XIX.

A mediados de 1920, el futurista soviético El Lissitzki diseñó dos galerías para exhibir el por entonces emergente arte abstracto. En el sexto capítulo planteo que las salas de exhibición de Lissitzki funcionan como extensiones de las ambiciones vanguardistas de transformar el museo tradicional en un archivo. Dirigidas a romper la unión entre la arquitectura museística y su régimen visual contemplativo, las salas de exhibición también proveen un vínculo crucial con el cine, medio tecnológico que ejemplifica la ambición del archivo moderno de registrar el tiempo en múltiples maneras. Aparte de incorporar el cine, la transposición de Lissitzky del archivo administrativo hacia el museo viaja a través de la investigación decimonónica de la vision binocular y los precursores mecánicos del cine, como el estroboscopio y el fenakistocopio.

Mi análisis del archivo en el arte de la postguerra ocupa el séptimo capítulo. Comienza con la fotografía. Mirando compilaciones fotográficas de artistas de la postguerra, tanto del Este como del Occidente - Susan Hiller, Gerhard Richter, Hans-Peter Feldmann, Walid Raad y Boris Mikhailov-, exploro la transición que va de un modelo de archivo dominado por la preocupación decimonónica por el registro y el tiempo contingente, hasta formas similares a las bases de datos que evitan el énfasis del siglo XIX en el orden cronológico y la lectura lineal. Propongo, además, que más allá de reaccionar al siglo XIX, el archivo / la base de datos en la fotografía de la postguerra, también responde a la crítica de la vanguardia a ese archivo y la monumentalización neohistoricista del archivo decimonónico que definió los años veinte y treinta. El último capítulo trata sobre las formas en que los artistas de la postguerra cuestionan la producción de objetos archivables en un contexto antropológico, cognitivo e institucional. La noción de "archivo en juego" está diseñada para intervenir críticamente en el punto de vista prevaleciente de que el archivo moderno no es más que una instancia de la tecnología; una memoria técnica cuyo funcionamiento está garantizado por sus bases racionales. 